\title{
Patient experience with subcutaneous immunoglobulin 20\%, lg20Gly, for primary immunodeficiency diseases: a prespecified post hoc analysis of combined data from 2 pivotal trials
}

Lisa M. Meckley ${ }^{1 *}$, Yanyu Wu' ${ }^{2}$ Diane Ito $^{2}$, Todd Berner ${ }^{3}$, Barbara McCoy ${ }^{4}$ and Leman Yel ${ }^{2}$

\begin{abstract}
Background: Often, patients with primary immunodeficiency diseases (PID), which are marked by the absence or loss of functional antibodies, require lifelong treatment with immunoglobulin (IG) replacement therapy administered either intravenously (intravenous immunoglobulin [IVIG]) or subcutaneously (subcutaneous immunoglobulin [SCIG]). In patients with PID, the 20\% SCIG product, Ig20Gly, was shown to be efficacious and well tolerated in 2 phase 2/3 trials conducted in North America and Europe. This analysis evaluated patient satisfaction with Ig20Gly therapy and treatment preferences.

Methods: This prespecified post hoc analysis showed combined data from 2 lg20Gly pivotal trials. Treatment satisfaction was assessed in the pre-lg20Gly period and after $\geq 11$ months of Ig20Gly treatment using the Life Quality Index (LQl; both studies) and the Treatment Satisfaction Questionnaire for Medication-9 (TSQM-9; North American study only). Treatment preference was assessed using a survey at the end of the European study. Median within-patient differences in LQI and TSQM-9 scores between the pre-lg20Gly period and the end of the lg20Gly treatment period were assessed using the Wilcoxon signed-rank test.
\end{abstract}

* Correspondence: lisa.meckley@takeda.com

DI and TB were employees of Baxalta US Inc., a Takeda company, at the time of the current study/research.

'Shire US Inc., a Takeda company, 650 E Kendall St, Cambridge, MA 02142, USA

Full list of author information is available at the end of the article

(c) The Author(s). 2020 Open Access This article is licensed under a Creative Commons Attribution 4.0 International License, which permits use, sharing, adaptation, distribution and reproduction in any medium or format, as long as you give appropriate credit to the original author(s) and the source, provide a link to the Creative Commons licence, and indicate if changes were made. The images or other third party material in this article are included in the article's Creative Commons licence, unless indicated otherwise in a credit line to the material. If material is not included in the article's Creative Commons licence and your intended use is not permitted by statutory regulation or exceeds the permitted use, you will need to obtain permission directly from the copyright holder. To view a copy of this licence, visit http://creativecommons.org/licenses/by/4.0/. The Creative Commons Public Domain Dedication waiver (http://creativecommons.org/publicdomain/zero/1.0/) applies to the data made available in this article, unless otherwise stated in a credit line to the data. 


\begin{abstract}
(Continued from previous page)
Results: A total of 113 patients ( $n=68$ [North American]; $n=45$ [Europe]) with PID were included in the analysis. In the combined LQI analysis $(n=110)$, significant improvements were observed in the treatment interference (median $\Delta:+2.8 ; P=0.006$ ) and therapy setting (median $\Delta:+5.6 ; P<0.0001)$ domains, and in the item-level scores for convenience (median $\Delta:+1.0 ; P<0.0001$ ) and interference with work/school (median $\Delta:+1.0 ; P=0.0001$ ) categories. In the subgroup analyses, significant improvements in the treatment interference and therapy setting domains and the convenience and interference with work/school items were observed for those who had previously received treatment outside the home, those who had previously received IVIG, and those in the North American study. Significant improvements were observed in the TSQM-9 treatment convenience domain (median $\triangle:+11.1 ; P<0.0001$ ) and selected item-level scores in the North American study. In the European study, most (88.9\%) patients preferred to continue Ig20Gly versus other IG treatments.

Conclusions: After $\geq 11$ months of taking Ig20Gly, patients reported high levels of treatment satisfaction, convenience, and preference for Ig20Gly, with consistent results across studies and use of multiple patientreported outcome measures.
\end{abstract}

Keywords: Ig20Gly, Immunoglobulin, Subcutaneous, Satisfaction, Preference, Patient experience

\section{Background}

Primary immunodeficiency diseases (PID) comprise a heterogeneous group of $>400$ congenital disorders characterized by a genetic defect in the adaptive or innate immune system [1]. Among the 6.2 million individuals affected worldwide [2], primary antibody deficiencies represent the most prevalent PID diagnosis, making up nearly $50 \%$ of cases [3]. Patients with PID are susceptible to recurrent, serious bacterial infections (SBIs) and, without appropriate management, can experience longterm sequelae, such as bronchiectasis, autoimmune and gastrointestinal disorders, and progressive lung disease. These complications, in turn, can adversely affect the patient experience, including social relationships and health-related quality of life (HRQoL), daily work, and school activities [4-9].

Immunoglobulin (IG) replacement therapy (IGRT) is the mainstay of treatment for PID marked by the absence or loss of functional antibodies, including agammaglobulinemia, common variable immune deficiency, specific antibody deficiency, and immunoglobulin G (IgG) subclass deficiencies [10]. Clinical evidence indicates that IG administered intravenously or subcutaneously in patients with PID is well tolerated, significantly reduces the frequency of infections, and may enhance HRQoL [11-19]. Effective treatment, however, typically requires intravenous IG (IVIG) or facilitated subcutaneous IG (SCIG) infusions given every 3 to 4 weeks [20], or conventional SCIG infusions administered more often (from daily to every 2 weeks) [11]. Because IGRT is lifelong and patient satisfaction is a key factor in adherence [21], researchers and healthcare providers have considerable interest in identifying methods for improving the treatment experience for patients.

CUVITRU (Ig20Gly; immune globulin subcutaneous [human] 20\%, Baxalta US Inc., a Takeda company,
Westlake Village, CA, USA) is a ready-for-use, sterile liquid preparation of highly purified, concentrated IgG antibodies that is approved in the United States and Europe for the treatment of PID in adults and children aged $\geq 2$ years [22, 23]. Because higher IG concentration reduces the infusion volume required, Ig20Gly treatment may enable shorter infusion duration compared with less concentrated SCIG products [12]. Two phase 2/3 multicenter, open-label clinical trials demonstrated the efficacy, pharmacokinetics, tolerability, and safety of Ig20Gly treatment in patients with PID in North America and Europe [11, 12]. The objective of this analysis was to understand the patient experience through the patients' treatment satisfaction and preferences with Ig20Gly therapy during the registration pivotal trials.

\section{Methods}

\section{Study design}

This prespecified post hoc analysis of data from the Ig20Gly phase $2 / 3$ pivotal trials was conducted in North America and Europe (NCT01218438 and NCT01412385).

The methods for these studies have been published previously $[11,12]$. Briefly, in period 1 (pre-Ig20Gly period) of the 4-period North American study, patients were treated with IVIG $10 \%$ administered at 3- or 4-week intervals for 13 weeks and then switched to weekly Ig20Gly infusions for periods 2 to 4 . Ig20Gly doses adjusted to $145 \%$ of the IVIG dose were administered for 12 to 16 weeks in period 2 and for 12 weeks in period 3. Patients were treated with individually adapted Ig20Gly doses for 40 weeks in period 4 [12].

In period 1 (pre-Ig20Gly period) of the 2-period European study, patients were treated with weekly SCIG 16\% for 12 weeks or IVIG $10 \%$ every 3 or 4 weeks for 13 weeks. Patients were assigned to the same route of administration 
that was used prior to entering the study. In period 2, patients were switched to weekly Ig20Gly infusions administered at a weekly equivalent dose for approximately 12 months [11]. Both studies complied with the Declaration of Helsinki and the international standards of Good Clinical Practice $[11,12]$.

\section{Study setting}

The North American study included patients from 15 sites in the United States and Canada; 96\% infused Ig20Gly at home [12]. The European study was conducted at 16 sites in 7 countries (Germany, Austria, Sweden, United Kingdom, Netherlands, Belgium, and Hungary), with $95.8 \%$ of patients receiving $\geq 1$ Ig20Gly infusion at home and $74.1 \%$ (1740 of 2349) of all Ig20Gly infusions being administered at home [11].

\section{Patient inclusion/exclusion criteria}

Inclusion criteria for the North American and European studies have been previously described [11, 12]. Briefly, both studies included patients aged $\geq 2$ years at screening with a documented diagnosis of PID requiring IGRT, a serum IgG trough level $>500 \mathrm{mg} / \mathrm{dL}$ at screening, and no SBIs $\leq 3$ months before screening $[11,12]$. Included patients received a stable monthly mean IgG dose equivalent to $300-1000 \mathrm{mg} / \mathrm{kg}$ for $\geq 12$ weeks before the first study treatment with Ig20Gly.

In the patient-experience analyses, additional exclusionary criteria were applied. For these analyses, patients were required to have $\geq 11$ months of data in the Ig20Gly treatment phase (periods 2-4 in the North American study or period 2 in the European study) and no missing data at the end of the respective Ig20Gly treatment periods.

\section{Outcomes}

\section{Overview}

Outcomes included summary domain scores, scores for prespecified selected items of the Life Quality Index (LQI; North America and Europe) and the Treatment Satisfaction Questionnaire for Medication-9 (TSQM-9; North America only), and responses to a treatment preference questionnaire (Europe only) (Table 1). This analysis used responses after treatment with Ig20Gly for all instruments from the end-of-study visit (or earlytermination visit). In addition, the responses to the LQI and TSQM-9 were analyzed in the pre-Ig20Gly period (IVIG only in the North American study and either IVIG or SCIG in the European study).

In the North American study, the LQI and TSQM-9 were completed by an observer (parent/caregiver) on behalf of a patient aged 2-12 years or by the patient if 13 years or older [12]. In the European study, the LQI and treatment-preference questionnaire were completed by an observer (parent/caregiver) on behalf of a patient aged 2-13 years or by patients if 14 years or older [11].

\section{Treatment satisfaction Life quality index}

The LQI is a 15-item validated measure assessing IG treatment satisfaction in the following 4 domains: (1) treatment interference, (2) therapy setting, (3) therapy-related problems, and (4) cost. Item scores in each domain are summed to derive a summary score for the respective domain. The range of possible scores varies by domain; however, all domain scores were scaled from 0 to 100 in this analysis. Higher scores indicated higher satisfaction (Table 1) $[11,12]$.

The present study analyzed summary scores for 3 domains (treatment interference, therapy-related problems, and therapy setting) and the individual item scores as follows: (1) "scheduled according to patient's convenience" (treatment interference); (2) "convenience" (therapy-related problems); and (3) "interference with work/ school" (therapy setting). For these 3 LQI domains, both raw and summary scale scores were calculated. At the item level, higher scores indicated higher satisfaction.

The individual LQI items assessed in this study were selected a priori by the authors based on each item's likelihood of being impacted by the route of IGRT administration. The cost domain was not analyzed because patients did not pay for treatments in these studies. Furthermore, the psychometric validation study for the LQI recommended that the questions related to costs should be treated with caution because the lack of cost transparency and the different health systems did not allow the patient to assess therapy costs [24].

\section{Treatment satisfaction questionnaire for medication}

The TSQM-9 is a self-administered, 9-item, validated measure that assesses treatment satisfaction in the following 3 domains: effectiveness, convenience, and global satisfaction. The present study analyzed the TSQM-9 summary domain scores and individual scores for 1 item each in the domains of convenience ("convenient/inconvenient to take medication as instructed") and global satisfaction ("overall satisfaction/dissatisfaction with medication"). Domain scores ranged from 0 to 100; higher scores indicated higher patient satisfaction (Table 1). For the 2 selected items, patients rated their satisfaction using a 7-point Likert scale, with higher scores indicating higher patient satisfaction.

\section{Treatment preference}

At the end-of-study visit, patients in the European study completed a nonvalidated survey, developed as a part of the clinical trial protocol. The survey assessed patient preference to continue Ig20Gly treatment versus 
Table 1 Patient-reported outcomes collected in the Ig20Gly North American and European phase 2/3 trials

\begin{tabular}{|c|c|c|c|c|c|}
\hline \multirow[t]{2}{*}{ Instrument } & \multirow[t]{2}{*}{ Domain score assessed } & \multirow[t]{2}{*}{ Concept } & \multirow[t]{2}{*}{ Specific item-level score assessed } & \multicolumn{2}{|l|}{ Study included } \\
\hline & & & & North American & European \\
\hline \multirow[t]{3}{*}{$\mathrm{LQ}^{\mathrm{a}}$} & $\begin{array}{l}\text { Treatment interference (scaled } \\
\text { score range: } 0-100 \text { ) }\end{array}$ & $\begin{array}{l}\text { - Interference with social/family life } \\
\text { - Time waiting } \\
\text { - Treatment is worthwhile } \\
\text { - Dependency on others } \\
\text { - Freedom to take trips or move } \\
\text { - Scheduled according to patient's } \\
\text { convenience }\end{array}$ & $\begin{array}{l}\text { Scheduled according to patient's } \\
\text { convenience (score range: } 1-7 \text { ) }\end{array}$ & $x$ & $x$ \\
\hline & $\begin{array}{l}\text { Therapy-related problems } \\
\text { (scaled score range: } 0-100 \text { ) }\end{array}$ & $\begin{array}{l}\text { - Convenience } \\
\text { - Painfulness } \\
\text { - Health improvement } \\
\text { - Anxiety or nervousness }\end{array}$ & Convenience (score range: $1-7$ ) & $x$ & $x$ \\
\hline & $\begin{array}{l}\text { Therapy setting (scaled score } \\
\text { range: } 0-100 \text { ) }\end{array}$ & $\begin{array}{l}\text { - Interference with work/school } \\
\text { - Given in a comfortable place } \\
\text { - Given in a pleasant atmosphere }\end{array}$ & $\begin{array}{l}\text { Interference with work/school } \\
\text { (score range: } 1-7 \text { ) }\end{array}$ & $x$ & $x$ \\
\hline \multirow[t]{3}{*}{ TSQM- $-9^{b}$} & $\begin{array}{l}\text { Effectiveness (score range: } \\
0-100 \text { ) }\end{array}$ & $\begin{array}{l}\text { - Ability of the medication to prevent } \\
\text { or treat conditions } \\
\text { - The way the medication relieves } \\
\text { symptoms } \\
\text { - Time before the medication works }\end{array}$ & - & $x$ & - \\
\hline & $\begin{array}{l}\text { Convenience (score range: } \\
0-100)\end{array}$ & $\begin{array}{l}\text { - Easy/difficult to use the medication } \\
\text { in its current form } \\
\text { - Easy/difficult to plan when to use the } \\
\text { medication each time } \\
\text { - Convenient/inconvenient to take the } \\
\text { medication as instructed }\end{array}$ & $\begin{array}{l}\text { Convenient/inconvenient to take } \\
\text { medication as instructed (score } \\
\text { range: } 1-7 \text { ) }\end{array}$ & $x$ & - \\
\hline & $\begin{array}{l}\text { Global satisfaction (score } \\
\text { range: } 0-100 \text { ) }\end{array}$ & $\begin{array}{l}\text { - Overall confidence that taking this } \\
\text { medication is a good thing } \\
\text { - Certainty that good things about } \\
\text { medication outweigh bad things } \\
\text { - Overall satisfaction/dissatisfaction } \\
\text { with medication }\end{array}$ & $\begin{array}{l}\text { Overall satisfaction/dissatisfaction } \\
\text { with medication (score range: } 1-7 \text { ) }\end{array}$ & $x$ & - \\
\hline $\begin{array}{l}\text { Treatment } \\
\text { preference }^{c}\end{array}$ & - & $\begin{array}{l}\text { - Like/dislike aspects of administration } \\
\text { - Preference to continue Ig20Gly }\end{array}$ & Multiple items & - & $x$ \\
\hline
\end{tabular}

${ }^{a}$ In the European study, the LQI was self-administered by patients aged $\geq 14$ years (observer: patient) and completed by parents/caregivers for patients aged 2-13 years (observer: parent/caregiver). In the North American study, the LQI was self-administered by patients aged $\geq 13$ years (observer: patient) and completed by parents/caregivers for patients aged $2-12$ years (observer: parent/caregiver)

${ }^{b}$ In the North American study, the TSQM-9 was self-administered by patients aged $\geq 13$ years (observer: patient) and completed by parents/caregivers for patients aged 2-12 years (observer: parent/caregiver)

IIn the European study, the treatment preference questionnaire was self-administered by patients aged $\geq 14$ years (observer: patient) and completed by parents/ caregivers for patients aged 2-13 years (observer: parent/caregiver).

Ig20Gly, immune globulin subcutaneous (human) 20\%: LQI, Life Quality Index; TSQM-9, Treatment Satisfaction Questionnaire for Medication-9

previous treatment. Additional preferences evaluated were: site of treatment (home, hospital, or other), frequency of administration, number of needle sticks per month, total time spent on treatment per month, ease of administration, potential to self-administer, ability to fit the treatment into personal schedule, overall convenience, time required, complexity of administration, and the ability to administer with no supervision.

\section{Statistical methods}

Continuous variables were summarized descriptively, using nonparametric methods (median, interquartile range). Categorical variables were expressed as a frequency $(\mathrm{N})$ and percentage of total (\%). The median within-patient differences (median $\Delta$ ) in LQI and TSQM9 scores between the end of the pre-Ig20Gly period and the end of the Ig20Gly treatment period were calculated. The differences in distributions of LQI and TSQM-9 scores between the pre-Ig20Gly period and the end of the study were assessed using the Wilcoxon signed-rank test. Therefore, the distribution of scores can have a statistically significant difference even if the median $\Delta$ is zero. Subgroup analyses were conducted to test for differences in the LQI and TSQM-9 scores between patients categorized by age group ( $2-17$ years, $\geq 18$ years), prior route of IG administration (IV, SC), and site of prior treatment (home, other setting [doctor's office, hospital, or infusion center]). The LQI was analyzed separately for the North American and European studies, with subgroups by prior route of administration also analyzed. In the European study, treatment preference at the end-of-study visit was analyzed overall and by age group, previous route of administration, 
and treatment setting. Statistical analyses were performed using SAS 9.3 (SAS Institute, Cary, NC, USA). A 2-sided $P$ value $<0.05$ was statistically significant.

\section{Results}

To briefly summarize the original trials, 49 subjects included in the European study [11] and 77 subjects included in the North American study [12] received Ig20Gly. The European study population was $61.2 \%$ male, with a median age of 17.0 years (range: 2-67 years) and a median weight of $63.0 \mathrm{~kg}$ (range: 12.9$140.0 \mathrm{~kg}$ ) [11]. The North American study population was $51.9 \%$ male, with a higher median age compared with that of the European study (36 years, range: 3-83 years), and median weight of $68.2 \mathrm{~kg}$ (range: $13.2-161.8$ $\mathrm{kg}$ ) [12]. In both trials, the median for completion of an infusion was $0.95 \mathrm{~h}$ and a median of 2 infusion sites was used $[11,12]$. In the European study, the median maximum infusion rate was $20 \mathrm{~mL} /$ hour/site (range: 2.5-60.0 $\mathrm{mL} /$ hour/site) and the median infusion volume was 16.6 $\mathrm{mL} / \mathrm{site}$ (range: $6.5-48.0 \mathrm{~mL} / \mathrm{site}$ ) [11]. In the North American study, the maximum infusion rate per site $(60 \mathrm{~mL} / \mathrm{h} /$ site [range: $4.4-180.0 \mathrm{~mL} /$ hour/site] $)$ and the median infusion volume per site $(39.5 \mathrm{~mL} / \mathrm{site}$ [range: 6.4-76.0 mL/site]) were higher compared with those of the European study [12].

Of 141 patients screened from the original trial populations, 113 patients completed the patientreported-outcomes assessments at the end of the pre-Ig20Gly period and fulfilled inclusion criteria for this analysis. The combined analysis of LQI scores included 110 patients from the North American $(n=$ $67)$ and European $(n=43)$ studies who also completed the assessment at the end of the study. All patients from the North American study who met the inclusion criteria provided complete data for the TSQM-9 $(n=68)$. Likewise, all patients from the European study who met inclusion criteria provided complete data for the treatment-preference questionnaire $(n=45)$.

Demographics and baseline clinical characteristics for the 113 patients from the combined study sample are shown in Table 2. Male patients and adults aged $\geq 18$ years comprised more than half (58.4\% each) of the combined study sample $(N=113)$. Most patients were white (93.8\%) and of non-Latino/Hispanic ethnicity (95.6\%). Common variable immune deficiency was the most common PID diagnosis (42.5\%), followed by specific antibody deficiency (30.1\%) and agammaglobulinemia (18.6\%). Before study entry, $76(67.3 \%)$ patients were treated with IVIG, most $(n=64,84.2 \%)$ of whom were infused outside the home. Nearly all patients on prior SCIG (91.9\%; 34/ 37) had infused at home.

\section{Changes in LQI scores \\ Combined analysis}

Median LQI scores for the pre-Ig20Gly period and end of study, $P$ values for the Wilcoxon signed-rank test of the distribution, and within-patient median $\Delta$ values for the combined analysis $(n=110)$ are shown in Fig. 1. Overall within-patient scores improved significantly for the treatment interference (median $\Delta:+2.8 ; P=0.006$ ) and therapy setting domains (median $\Delta:+5.6 ; P<0.0001$ ). Significant within-patient differences were observed for those who previously received treatment outside the home (treatment interference: median $\Delta:+2.8, P=0.001$; therapy setting: median $\Delta:+11.1 ; P<0.0001)$, previously received IVIG (treatment interference: median $\Delta:+2.8, P=0.003$; median $\Delta:+11.1$, therapy setting: $P<0.0001)$, and were in the North American study (treatment interference: median $\Delta:+2.8, P=0.013$; therapy setting: median $\Delta:+5.6$, $P<0.0001$ ). For both patients aged $2-17$ and $\geq 18$ years, the within-patient difference in therapy settings scores was significant (median $\Delta:+5.6, P=0.001$ ).

Figure 2 shows the scores for selected LQI items for the overall population. Statistically significant withinpatient differences from the pre-Ig20Gly period to the end of the study period were observed for convenience $(P<0.0001)$, scheduled according to patient's convenience $(P=0.011)$, and interference with work/school $(P<0.0001)$; median $\Delta$ values were $+1.0,0.0$, and +1.0 , respectively. Statistically significant within-patient differences were observed for patients who were previously treated outside the home, aged $\geq 18$ years, and previously treated with IVIG for all selected item scores.

\section{North American study}

At the end of the Ig20Gly treatment period, patients in the North American study $(n=67 ; 1$ patient did not complete the LQI) perceived significantly greater satisfaction in the treatment interference $(P=0.013)$ and therapy setting $(P<0.0001)$ domains compared with the preIg20Gly period (Fig. 1); median within-patient $\Delta$ values were +2.8 and +5.6 , respectively. In the therapy setting domain, patients reported significant improvement both among those who switched from prior IVIG $(P<0.0001)$ and those previously receiving SCIG $(P=0.005)$; median within-patient $\Delta$ values were +11.1 and +5.6 , respectively. However, results were not statistically different in the treatment interference and therapy-related problems domains between those who previously received IVIG and SCIG (Additional file Figure S1).

At the end of the Ig20Gly treatment period, significantly improved scores were observed for the selected LQI items convenience $(P<0.0001)$ and interference with work/school $(P<0.0001)$ LQI item scores (Fig. 2$)$. Median within-patient $\Delta$ values were +1.0 for both convenience and interference with work/school. Improvements 


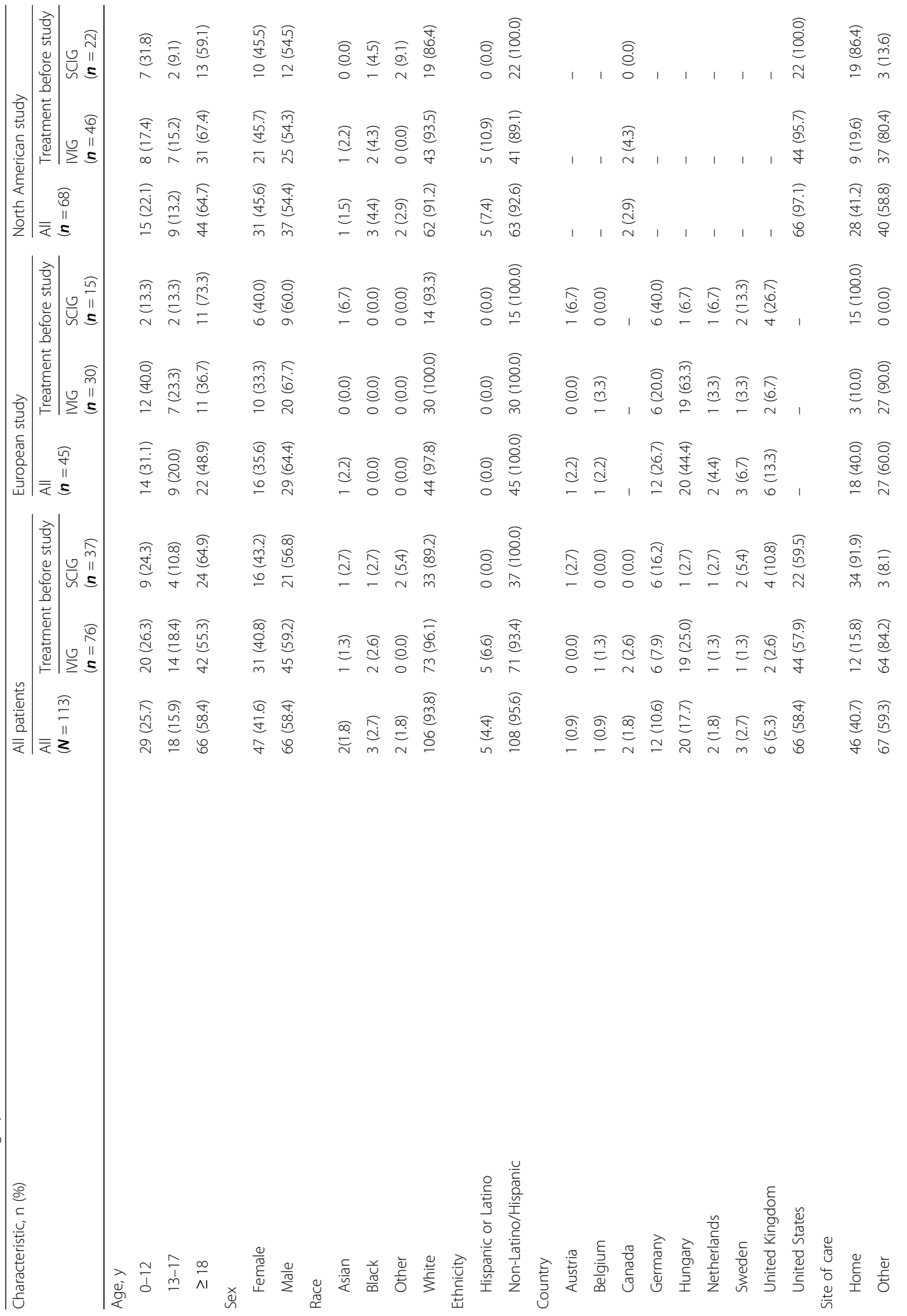




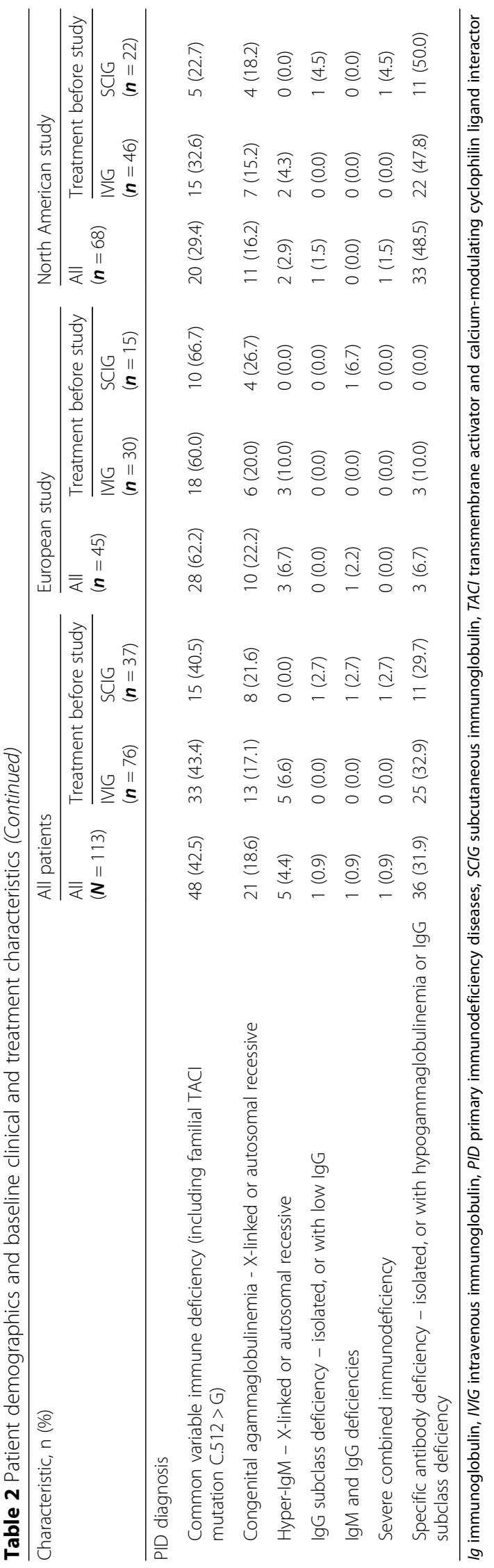




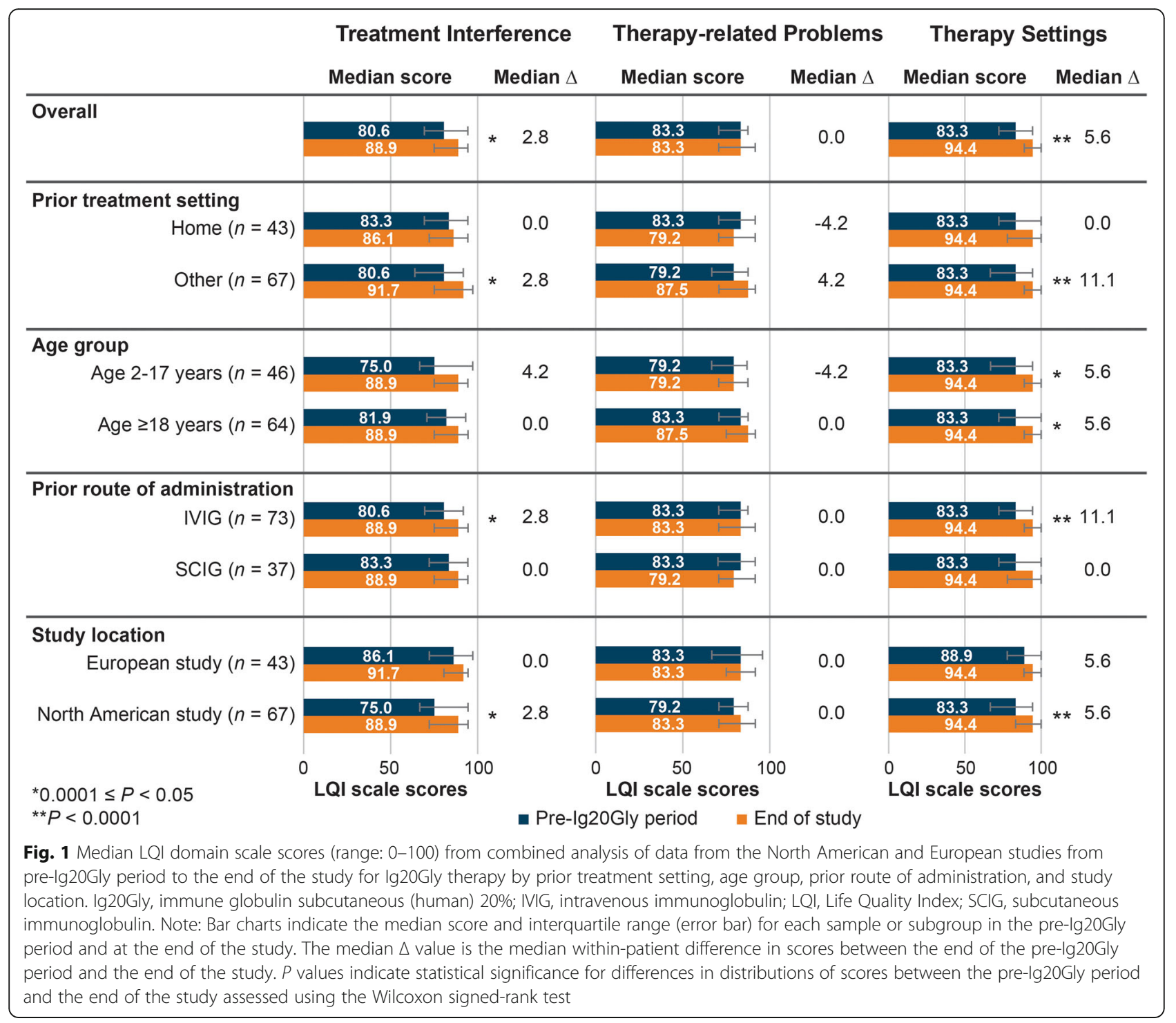

for these items were observed regardless of prior route of administration (Additional file Figure S1). Satisfaction with scheduling treatment according to the patient's convenience did not improve significantly in the total population or after stratifying by the prior route of administration (Additional file Figure S1).

\section{European study}

Patients in the European study $(n=43)$ showed no significant changes in any of the median domain and item scores at the end of the study compared with the preIg20Gly period (Figs. 1 and 2). However, patients who switched from IVIG $(n=28)$ perceived statistically significant improvements after treatment with Ig20Gly in the treatment interference $(P=0.018)$ and therapy setting $(P=0.005)$ domains; median within-patient $\Delta$ values were + 4.2 and +11.1 , respectively (Additional file Figure S2).
Significant within-patient improvements were also observed for the LQI items assessing scheduled according to patient's convenience (median $\Delta: 0.0 ; P=0.004$ ) and interference with work/school (median $\Delta:+1.0 ; P=0.003$ ); median $\Delta$ values were 0.0 and +1.0 , respectively (Additional file Figure S2). Patients who previously received SCIG reported no significant changes.

\section{Changes in TSQM-9 (North American study)}

Figure 3 shows median TSQM-9 scores for the preIg20Gly period and end of study, $P$ values for the Wilcoxon signed-rank test of the distribution, and withinpatient median $\Delta$ values from the North American study. At the end of the Ig20Gly treatment period, patients $(n=68)$ reported significantly higher scores in the convenience domain (median within-patient $\Delta:+11.1$; $P<0.0001)$. Convenience domain scores improved 


\begin{tabular}{|c|c|c|c|c|c|c|}
\hline & \multicolumn{2}{|c|}{$\begin{array}{l}\text { Scheduled According to } \\
\text { Patient's Convenience }\end{array}$} & \multicolumn{2}{|c|}{ Convenience } & \multicolumn{2}{|c|}{$\begin{array}{l}\text { Interference With } \\
\text { Work/School }\end{array}$} \\
\hline & Median score & Median $\Delta$ & Median score & Median $\Delta$ & Median score & Median $\Delta$ \\
\hline Overall & & * 0.0 & 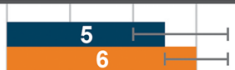 & ** 1.0 & & $* * 1.0$ \\
\hline \multicolumn{7}{|l|}{ Prior treatment setting } \\
\hline Home $(n=43)$ & & 0.0 & & 0.0 & & 0.0 \\
\hline Other $(n=67)$ & & * 0.0 & & ** 1.0 & & $* * 1.0$ \\
\hline \multicolumn{7}{|l|}{ Age group } \\
\hline Age $2-17$ years $(n=46)$ & & 0.0 & & * 0.5 & & * 1.0 \\
\hline Age $\geq 18$ years $(n=64)$ & & * 0.0 & -1 & * 1.0 & -1 & ** 1.0 \\
\hline \multicolumn{7}{|l|}{ Prior route of administration } \\
\hline IVIG $(n=73)$ & 6 & * 0.0 & 6 & ** 1.0 & & $* * 1.0$ \\
\hline $\operatorname{SCIG}(n=37)$ & 7 & 0.0 & $\begin{array}{l}6 \\
6\end{array}$ & 0.0 & 6 & 0.0 \\
\hline \multicolumn{7}{|l|}{ Study location } \\
\hline European study $(n=43)$ & & 0.0 & -1 & 0.0 & -1 & 0.0 \\
\hline North American study $(n=67)$ & $\frac{6}{6}$ & 0.0 & 5 & ** 1.0 & ـ & $* * 1.0$ \\
\hline & 6 & 8 & 6 & 8 & $\begin{array}{llll}0 & 2 & 4 & 6\end{array}$ & 8 \\
\hline \multirow{2}{*}{$\begin{array}{l}{ }^{*} 0.0001 \leq P<0.05 \\
{ }^{*} P<0.0001\end{array}$} & LQI item scores & & LQI item scores & & LQI item scores & \\
\hline & & - Pre-lg2 & OGly period & nd of study & & \\
\hline $\begin{array}{l}\text { Fig. } 2 \text { Median LQI selected item sc } \\
\text { pre-Ig20Gly period to end of study } \\
\text { Ig20Gly, immune globulin subcutan } \\
\text { immunoglobulin. Note: Bar charts in } \\
\text { period and at the end of the study. } \\
\text { period and the end of the study. } \\
\text { and the end of the study assessed }\end{array}$ & $\begin{array}{l}\text { ores (range: } 0-8 \text { ) from } \\
\text { for Ig20Gly therapy b } \\
\text { heous (human) } 20 \% \text {; I } \\
\text { ndicate the median sc } \\
\text { The median } \Delta \text { value } \\
\text { values indicate statist } \\
\text { using the Wilcoxon si }\end{array}$ & $\begin{array}{l}\text { combined anal } \\
\text { prior treatmen } \\
\text { IG, intravenous } \\
\text { ore and interqu } \\
\text { s the median w } \\
\text { cal significance } \\
\text { gned-rank test }\end{array}$ & $\begin{array}{l}\text { ysis of data from the } \\
\text { it setting, age group, } \\
\text { immunoglobulin; LQ } \\
\text { artile range (error bar } \\
\text { ithin-patient differen } \\
\text { for differences in dist }\end{array}$ & $\begin{array}{l}\text { North American } \\
\text { orior route of adr } \\
\text { Life Quality Inde } \\
\text { s) for each sampl } \\
\text { e in scores betw } \\
\text { ibutions of score }\end{array}$ & $\begin{array}{l}\text { and European studie } \\
\text { Iministration, and stud } \\
\text { ex; SCIG, subcutaneou } \\
\text { le or subgroup in the } \\
\text { veen the end of the } p \\
\text { es between the pre-lo }\end{array}$ & $\begin{array}{l}\text { s from } \\
\text { dy location. } \\
\text { is } \\
\text { pre-lg20Gly } \\
\text { pre-lg20Gly } \\
\text { 20Gly period }\end{array}$ \\
\hline
\end{tabular}

significantly regardless of prior route of administration, age group, or prior treatment setting. Significantly significant within-patient improvements in global satisfaction were observed only for patients who previously received SCIG (median $\Delta:+7.1 ; P=0.001$ ). There was no statistically significant difference in the effectiveness domain overall or for any subgroup (Fig. 3).

TSQM-9 item level scores are shown in Fig. 4. Significant within-patient increases in scores for convenience of taking medication as instructed (median $\Delta:+1.0 ; P<0.0001)$ and overall satisfaction/dissatisfaction with medication (median $\Delta: 0.0 ; \quad P=0.004$ ) were observed. Item-level scores for the convenience of taking medication as instructed significantly improved for those who were previously treated outside the home $(P<0.0001)$, those who were previously treated with IVIG $(P<0.0001)$, and for patients who were aged $2-17(P=0.018)$ and $\geq 18$ years $(P=0.0002)$. Median within-patient $\Delta$ values were +1.0 for patients who were previously treated outside the home, those who were previously treated with IVIG and both age groups. The distribution of the item-level scores (Fig. 4) for overall satisfaction/dissatisfaction with medication improved significantly for patients previously treated at home, those previously treated with SCIG, and both age groups.

\section{Treatment preference (European study)}

Overall, 88.9\% (40/45) of patients in the European study stated that they would prefer to continue Ig20Gly therapy over other treatments. All subgroups had similarly 


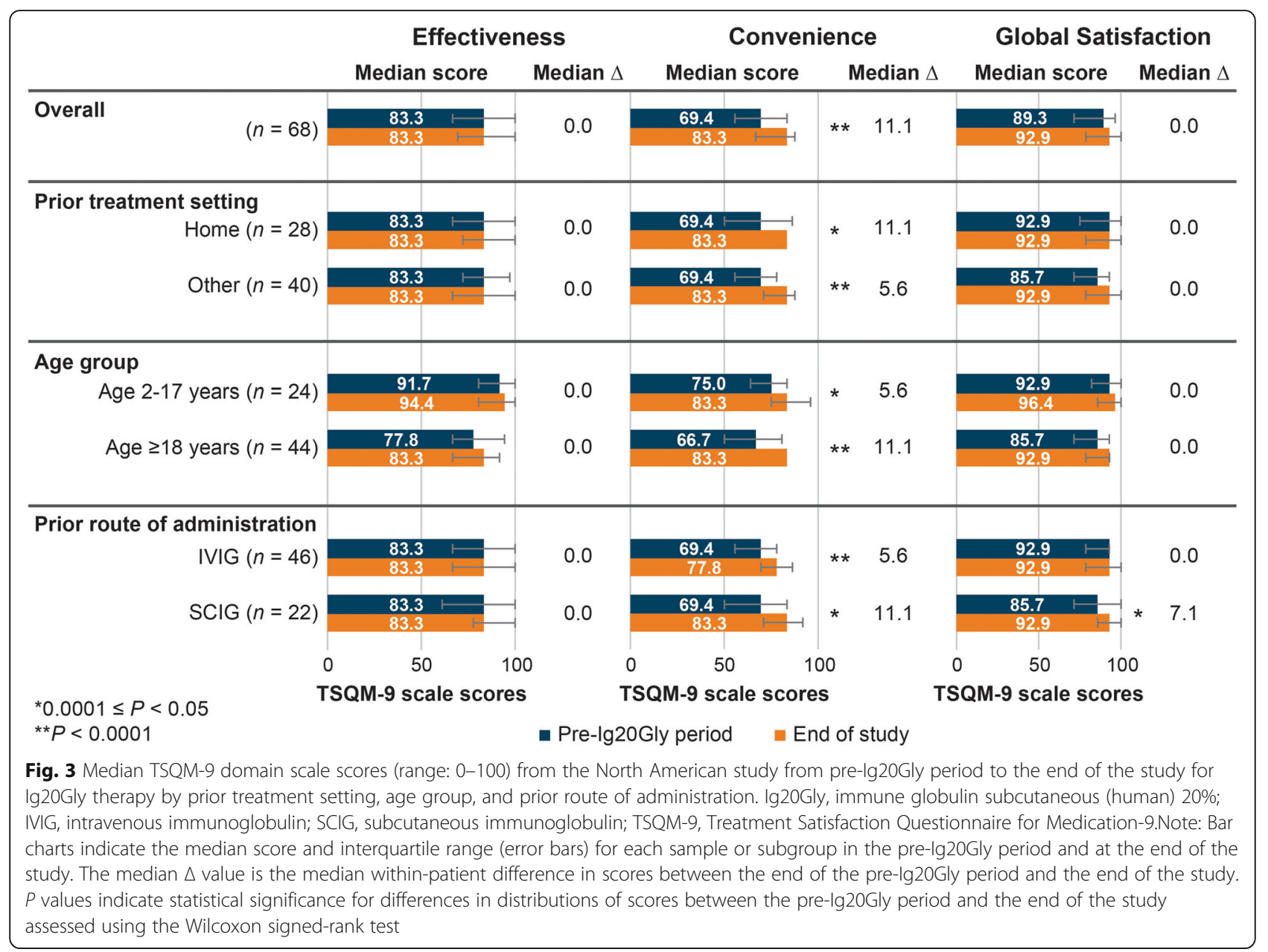

high proportions of patients favoring continuation of Ig20Gly treatment (Fig. 5). The patients also preferred to administer in the home $(88.9 \% ; 40 / 45)$, although only one-third (33.3\%) had done so previously (data not shown in figure).

In the European study, the attributes most strongly preferred by patients (based on the percentages of "like" or "like very much" responses) included the ability to fit the treatment into his or her own schedules (95.6\%) and the ability to administer without supervision (95.6\%), overall convenience (93.3\%), the potential to selfadminister (91.1\%), and ease of administration (91.1\%) (Additional file Figure S3). Attributes that were most commonly "disliked/disliked very much" included the frequency of administration (15.5\%) and the number of needle sticks per month (13.3\%) The subgroup analyses demonstrated similar trends in attribute-preference ratings (data not shown).

\section{Discussion}

Over a dozen IGRT products are available in North America and Europe, which vary with respect to IG concentration, infusion frequency, route of administration, and other considerations [25]. In a recent metaanalysis, IGRT products were equally effective for preventing infections in patients who have PID, regardless of the route of administration [26]. In terms of safety and tolerability, patients receiving SCIG therapies generally report localized infusion-site reactions, whereas those receiving IVIG therapies are more likely to experience systemic adverse reactions [27-29]. Therefore, treatment decisions are greatly influenced by factors, including tolerability and patient preference.

This analysis evaluated various aspects of the patient experience with Ig20Gly therapy in North America and Europe. The LQI indicated improvements in satisfaction related to treatment interference and therapy setting in the overall population; however, the analysis found some differences in the reported experiences of the subpopulations. Patients perceived improved convenience of Ig20Gly treatment compared with previous therapy as measured by the TSQM-9. After $\geq 11$ months on Ig20Gly therapy, the European study found that $89 \%$ of patients wanted to continue, with similar findings across all subgroups, including those 


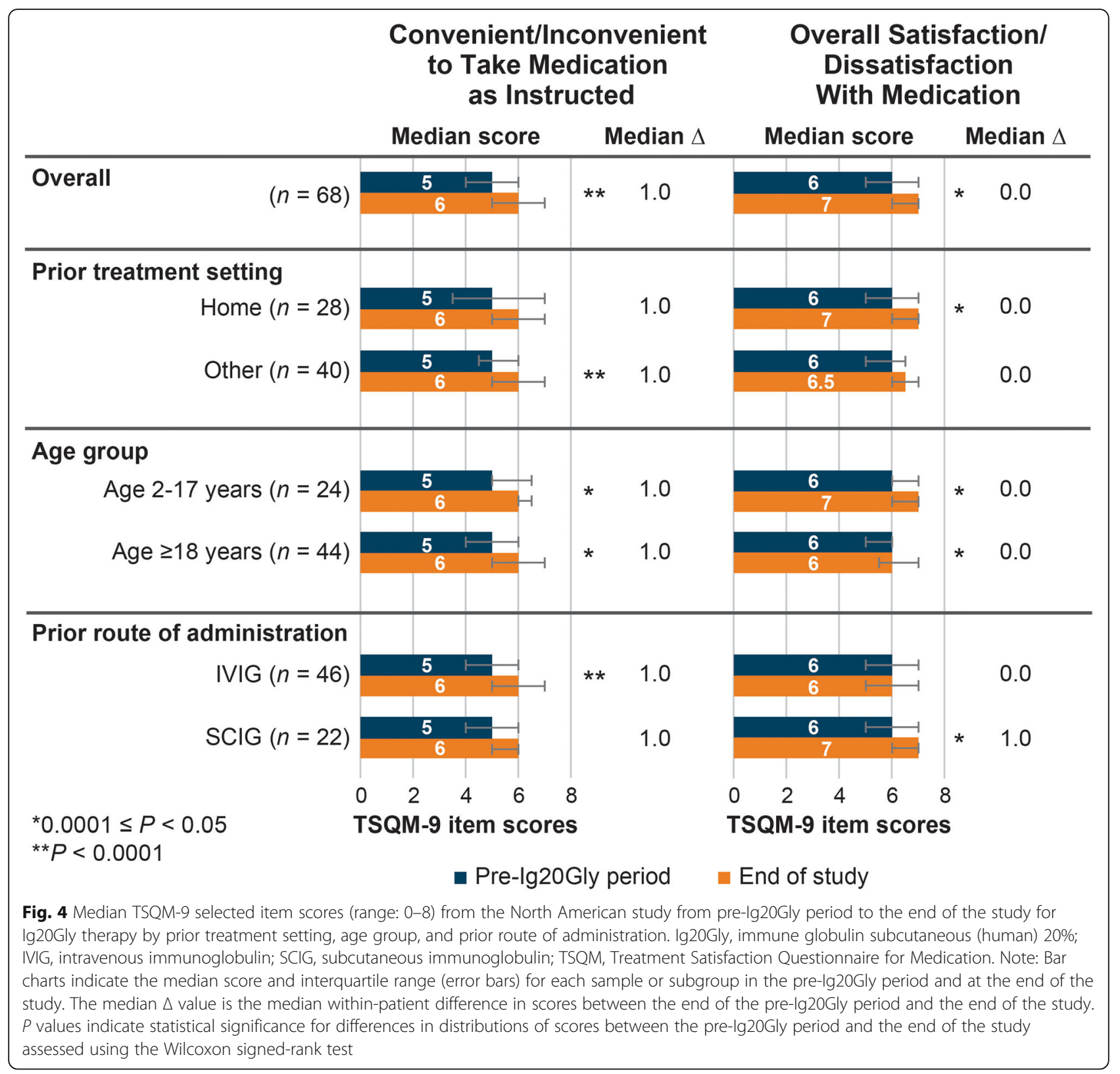

patients who had been previously treated with another SCIG. Overall, the combined findings from the LQI, TSQM-9, and treatment-preference surveys indicated that patients had improved treatment experience after Ig20Gly treatment compared with previous therapies.

The combined LQI analyses confirmed the findings of the North American study, which showed that patients who switched from IVIG to Ig20Gly treatment for approximately 1 year were significantly more satisfied with respect to the interference (interference with work or school item), therapy settings (therapy settings domain), and convenience (convenience item) aspects of treatment. Although the European study reported more modest changes, patients in the European study had generally higher baseline LQI scores than those in the North American study, suggesting that the former population may have been relatively more satisfied before initiating Ig20Gly treatment. One-third (15/45) of the patients in the European study had switched from prior SCIG treatment. Given that these patients had received SCIG in both periods 1 and 2, higher baseline scores and smaller effects were hypothesized. This apparent "ceiling effect" may have also accounted for subgroup differences in the combined analysis. Patients treated previously at home or with prior SCIG tended to report greater satisfaction at baseline compared with those switching from other settings or IVIG. Therefore, patients having prior IVIG (but not prior SCIG) treatment perceived significant improvement in the 


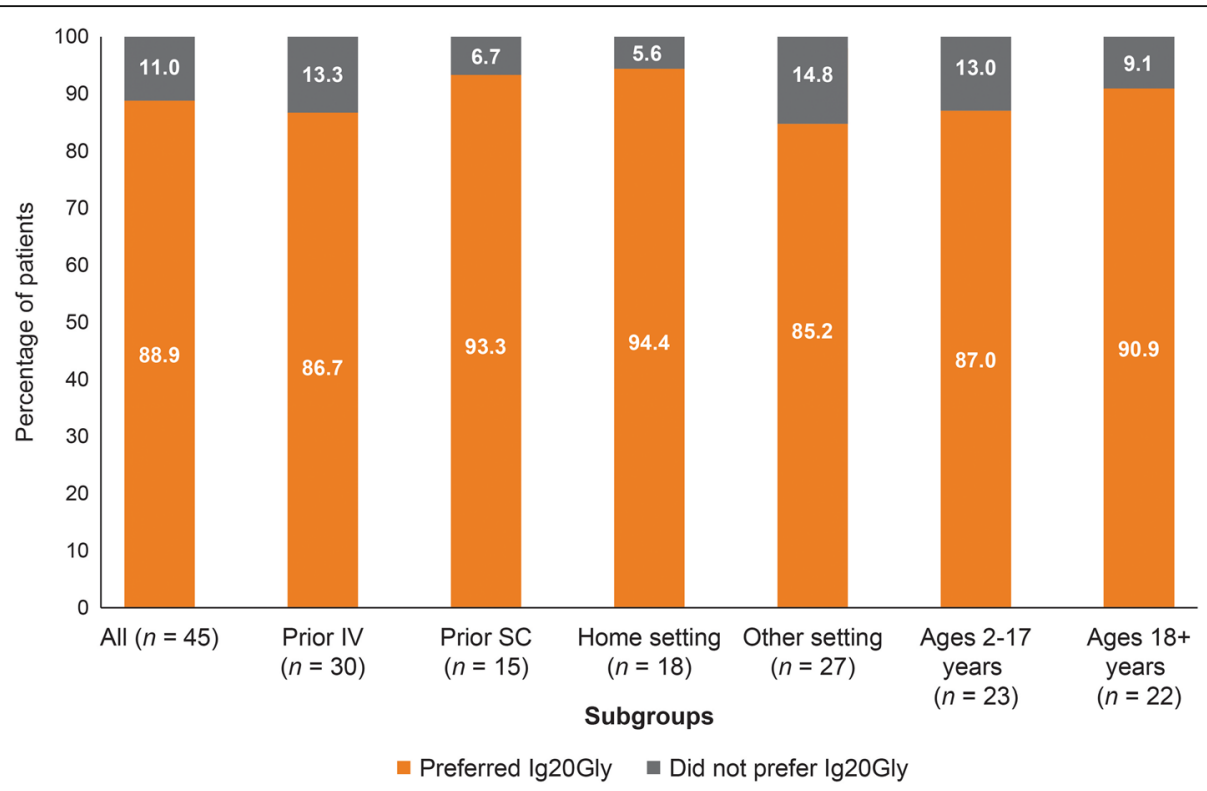

Fig. 5 Treatment preference to continue Ig20Gly treatment in the European study. Ig20Gly, immune globulin subcutaneous (human) 20\%; IV, intravenous; SC, subcutaneous

treatment interference domain, whereas patients treated previously in other settings, but not at home, were significantly more satisfied in the therapy setting domain. Similarly, itemlevel LQI scores in the combined analyses did not increase significantly for patients continuing treatment at home.

Overall, the present LQI findings are consistent with the results of several clinical trials and real-world studies, which indicated that SCIG treatment or treatment in the home had higher reported satisfaction compared with IVIG or hospital-based treatment [21, 30]. Mean scores for all LQI domains increased significantly from baseline to 12 weeks among patients who switched to home administration of 20\% SCIG IgPro20 (Hizentra, CSL Behring AG, Bern, Switzerland) from IVIG or other SCIG in 2 phase 3 clinical studies [31]. In the prospective, observational, French cohort "Visages" study $(N=116)$ [21], satisfaction measured in the LQI therapy setting domain was significantly higher for home-based SCIG compared with hospital-based IVIG and satisfaction in the treatment interference domain was significantly higher for homebased SCIG compared with home-based IVIG; however, hospital-based IVIG and home-based IVIG had no differential effects. The route of administration and site of treatment had no significant impact on satisfaction concerning therapy-related problems [21]. The US IDEaL (Immunoglobulin Diagnosis, Evaluation, and Key Learnings) patient registry survey [30] found that after 12 months of homebased SCIG (80\%) or home-based IVIG (20\%) treatment, 92\% (108/118) of respondents reported positive views regarding treatment convenience. Although the LQI convenience scores did not differ between the groups, over time, these positive perceptions decreased with IVIG and increased with SCIG treatment [30]. In addition, several nonrandomized prospective studies conducted in Europe have similarly reported improvements in LQI scores for patients who switched from hospital-based IVIG to home-based SCIG treatment $[15,24,32]$.

The TSQM-9 responses in the present analysis showed that patients in the North American study valued the convenience of home-based Ig20Gly therapy, regardless of prior route of administration, age group, or prior treatment setting, based on the responses to the overall convenience domain. The global satisfaction domain scores improved significantly only in patients on prior SCIG; however, on the specific item "overall satisfaction/ dissatisfaction with medication," most subgroups, except patients previously treated with IVIG and outside the home, had higher score distributions. The difference between the results in the global satisfaction domain score and the overall satisfaction item may be because the domain also includes confidence and certainty regarding the positive aspects of treatment. In contrast to the LQI findings, the TSQM-9 scores by domain prior to treatment with Ig20Gly were similar across subgroups defined by previous route of administration and previous treatment setting, but not by age group.

The TSQM was administered in 2 other studies of IG switching [33, 34]. In those studies, switching patients from SCIG 16\% (Vivaglobin, CSL Behring GmbH, Marburg, Germany) to a 20\% SCIG IgPro20 (Hizentra, CSL Behring AG, Bern, Switzerland), no statistically significant 
improvements were found [33, 34]. However, several differences between these IgPro20 studies and the present study of Ig20Gly should be noted: The IgPro20 treatment was shorter (24 weeks) than in the studies used in the present analysis, and Ig20Gly and IgPro20 treatments differed in infusion characteristics, with the former allowing for fewer infusion sites and faster infusion rates, leading to shorter infusion times [33, 34]. Similar to the convenience benefits of Ig20Gly therapy observed in the present study, study participants in the IgPro20 study were more satisfied with the frequency and scheduling of infusions after using the 20\% SCIG treatment $[33,34]$.

Patients in the present Ig20Gly European study most strongly preferred treatment aspects that enabled more control and self-administration, which are attributes generally ascribed to home-based SCIG therapy. These preferences mirrored prior observations of the 2011 International Patient Organisation for Primary Immunodeficiencies survey $(N=300)$, which found that SCIG respondents significantly preferred self-administration compared with an appointment with a healthcare provider $(P<0.05)$ [35]. IVIG respondents significantly favored once-monthly treatment compared with more frequent treatments and a single needle stick per infusion compared with 2 or 3 needle sticks. However, both groups significantly preferred home-based therapy to clinic-based options $(P<0.05)$ [35].

This analysis has several limitations; the primary limitation is that the data were collected in an investigational setting, which may not reflect real-world treatment experiences. The source studies $[11,12]$ included patients from many countries and sites, with potentially differing underlying clinical characteristics and dissimilar practice patterns, both of which may influence the patient experience. A stratified analysis by site was not conducted because the subgroups would have been too small for meaningful statistical analysis. A $P$ value correction method for multiple comparisons, such as Bonferroni adjustment, was not used in this analysis; however, for most comparisons, using such a correction method would not have changed the statistical significance of the results. Finally, because the TSQM-9 and the treatment-preference questionnaire were not administered in both studies, we could not combine these results across the European and North American studies. Future studies evaluating the patient experience in realworld settings will expand the evidence base for improving the patient experience among those treated with IG for PID.

\section{Conclusion}

Selection of an IG product and route of administration should consider a wide range of clinical and patient parameters. At the appropriate dosing regimen, SCIG is as efficacious as IVIG, while offering potential advantages, such as the ability to self-administer at home, fewer systemic adverse reactions, higher serum IgG trough levels, and improvement in the patient experience. The choice between IG treatments and, ultimately, achievement of treatment success may depend on the patient's expectations, preferences, and satisfaction with treatment. Prescribers can consider high levels of patient-reported satisfaction, patient convenience, and preference for Ig20Gly therapy when selecting an appropriate IG treatment option for their patients with PID.

\section{Supplementary information}

Supplementary information accompanies this paper at https://doi.org/10. 1186/s12865-020-00346-z.

Additional file 1 : Figure S1. LQI Domain and Item Subgroup Scores by Prior Route of Administration From the North American Study ( $N=67)$

Additional file 2 : Figure S2. LQI Domain and Item Subgroup Scores by Prior Route of Administration From the European Study $(N=43)$

Additional file 3 : Figure S3. Preference for Treatment Attributes in the European Study

\section{Abbreviations}

HRQoL: Health-related quality of life; IDEaL: Immunoglobulin Diagnosis, Evaluation, and Key Learnings; IG: Immunoglobulin; Ig20Gly: CUVITRU, 20\% subcutaneous immunoglobulin product; IgG: Immunoglobulin G; IgPro20: Hizentra, 20\% subcutaneous immunoglobulin product; IGRT: Immunoglobulin replacement therapy; IV: Intravenous; IVIG: Intravenous immunoglobulin; LQI: Life Quality Index; PID: Primary immunodeficiency diseases; SBI: Serious bacterial infection; SC: Subcutaneous;

SCIG: Subcutaneous immunoglobulin; TSQM-9: Treatment Satisfaction Questionnaire for Medication-9

\section{Acknowledgements}

The authors thank the patients who participated in these trials, any caregivers, study-site personnel, and the investigators.

\section{Authors' contributions}

LMM conceived of and designed the analysis, interpreted the data, and drafted the manuscript. YW conceived of and designed the analysis, performed the statistical analysis, and interpreted the data. DI designed the analysis. TB conceived of and designed the analysis. BM and LY acquired and interpreted the data. All authors read and approved the final manuscript.

\section{Funding}

This study, including study design, collection, analysis, and interpretation of the data, was funded by Baxalta US Inc., a member of the Takeda group of companies, Lexington, MA, USA. Beena John, PhD, and Lisa M. Klumpp Callan, PhD, of C4 MedSolutions, LLC, Yardley, PA, USA, and Karen Kurtyka, MPH, of Oxford PharmaGenesis Inc., Newtown, PA, USA, provided editorial support, which was funded by Baxalta US Inc., a member of the Takeda group of companies.

\section{Availability of data and materials}

The datasets, including the redacted study protocols, redacted statistical analysis plans, and individual participants data supporting the results reported in this article, will be available 3 months after the submission of a request, to researchers who provide a methodologically sound proposal. The data will be provided after its de-identification, in compliance with applicable privacy laws, data protection and requirements for consent and anonymization. Please contact Lisa Meckley, the corresponding author of this study, to request the data. 


\section{Ethics approval and consent to participate}

This was a post hoc study and did not require ethics approval and consent. The source studies for these data obtained relevant ethics approvals, as stated in the source publications.

\section{Consent for publication}

Not applicable - no identifiable data from any individuals are included in this analysis.

\section{Competing interests}

Drs. Meckley, Wu, Yel, and McCoy are employees of the Takeda group of companies. Dr. Berner and Ms. Ito were employed by the Takeda group of companies at the time the study was conducted.

\section{Author details}

'Shire US Inc., a Takeda company, 650 E Kendall St, Cambridge, MA 02142, USA. ${ }^{2}$ Baxalta US Inc., a Takeda company, Cambridge, MA, USA. ${ }^{3}$ Baxalta US Inc., a Takeda company, Chicago, IL, USA. ${ }^{4}$ Baxalta Innovations GmbH, a Takeda company, Vienna, Austria.

Received: 11 October 2019 Accepted: 24 March 2020

Published online: 04 May 2020

\section{References}

1. Tangye SG, Al-Herz W, Bousfiha A, Chatila T, Cunningham-Rundles C, Etzioni A, Franco JL, Holland SM, Klein C, Morio T, et al. Human inborn errors of immunity: 2019 update on the classification from the International Union of Immunological Societies Expert Committee. J Clin Immunol. 2020;40(1):24-64

2. Bousfiha AA, Jeddane L, Ailal F, Benhsaien I, Mahlaoui N, Casanova JL, Abel L. Primary immunodeficiency diseases worldwide: more common than generally thought. J Clin Immunol. 2013;33(1):1-7.

3. Modell V, Knaus M, Modell F, Roifman C, Orange J, Notarangelo LD. Global overview of primary immunodeficiencies: a report from Jeffrey Modell centers worldwide focused on diagnosis, treatment, and discovery. Immunol Res. 2014;60(1):132-44.

4. Immune Deficiency Foundation. IDF Advocate. The National Newsletter of the Immune Deficiency Foundation. Diagnosis-how long does it take? Fall 2008 https://primaryimmune.org/wp-content/uploads/2011/04/Number-59-Fall-2 008.pdf.

5. Immune Deficiency Foundation. Treatment experiences and preferences among patients with primary immunodeficiency diseases: National Survey of Patients (2008). Accessed September 2019. https://primaryimmune.org/ sites/default/files/publications/Treatment-Experiences-and-Preferencesamong-Patients-with-Primary-Immunodeficiency-Disease-National-Survey-ofPatients-2008_1.pdf.

6. Kuburovic N, Pasic S, Susic G, Stevanovic D, Kuburovic V, Zdravkovic S, Petrovic M, Pekmezovic T. Health-related quality of life, anxiety, and depressive symptoms in children with primary immunodeficiencies. Patient Preference Adherence. 2014;8:323-30.

7. Mozaffari H, Pourpak Z, Pourseyed S, Moin M, Farhoodi A, Aghamohammadi A, Movahedi M, Gharagozlou M, Entezari N. Health-related quality of life in primary immune deficient patients. Iran J Allergy Asthma Immunol. 2006;5(1):23-7.

8. Blaese RM, Bonilla FA, Stiehm ER, Younger ME, eds. Patient \& Family Handbook for Primary Immunodeficiency Diseases. Fifth ed. 2013. https:// primaryimmune.org/sites/default/files/publications/IDF-Patient-FamilyHandbook-5th-Edition-2015-Reprint.pdf.

9. Sadeghi B, Abolhassani H, Naseri A, Rezaei N, Aghamohammadi A Economic burden of common variable immunodeficiency: annual cost of disease. Expert Rev Clin Immunol. 2015;11(5):681-8.

10. Bonilla FA, Khan DA, Ballas ZK, Chinen J, Frank MM, Hsu JT, Keller M, Kobrynski LJ, Komarow HD, Mazer B, et al. Practice parameter for the diagnosis and management of primary immunodeficiency. J Allergy Clin Immunol. 2015;136(5):1186-205 e1181-1178.

11. Borte M, Krivan G, Derfalvi B, Marodi L, Harrer T, Jolles S, Bourgeois C, Engl W, Leibl H, McCoy B, et al. Efficacy, safety, tolerability and pharmacokinetics of a novel human immune globulin subcutaneous, 20\%: a phase 2/3 study in Europe in patients with primary immunodeficiencies. Clin Exp Immunol. 2017;187(1):146-59.

12. Suez D, Stein M, Gupta S, Hussain I, Melamed I, Paris K, Darter A, Bourgeois C, Fritsch S, Leibl H, et al. Efficacy, safety, and pharmacokinetics of a novel human immune globulin subcutaneous, $20 \%$ in patients with primary immunodeficiency diseases in North America. J Clin Immunol. 2016;36(7): 700-12.

13. Nicolay U, Kiessling P, Berger M, Gupta S, Yel L, Roifman CM, Gardulf A, Eichmann F, Haag S, Massion C, et al. Health-related quality of life and treatment satisfaction in north American patients with primary immunedeficiency diseases receiving subcutaneous lgG self-infusions at home. J Clin Immunol. 2006;26(1):65-72.

14. Fasth A, Nystrom J. Quality of life and health-care resource utilization among children with primary immunodeficiency receiving home treatment with subcutaneous human immunoglobulin. J Clin Immunol. 2008;28(4):370-8.

15. Gardulf A, Nicolay U, Math D, Asensio O, Bernatowska E, Bock A, CostaCarvalho BT, Granert C, Haag S, Hernandez D, et al. Children and adults with primary antibody deficiencies gain quality of life by subcutaneous lgG selfinfusions at home. J Allergy Clin Immunol. 2004;114(4):936-42.

16. Wasserman RL, Melamed I, Kobrynski L, Strausbaugh SD, Stein MR, Sharkhawy M, Engl W, Leibl H, Sobolevsky L, Gelmont D, et al. Efficacy, safety, and pharmacokinetics of a 10\% liquid immune globulin preparation (GAMMAGARD LIQUID, 10\%) administered subcutaneously in subjects with primary immunodeficiency disease. J Clin Immunol. 2011;31(3):323-31.

17. Fasth A, Nystrom J. Safety and efficacy of subcutaneous human immunoglobulin in children with primary immunodeficiency. Acta Paediatr. 2007;96(10):1474-8.

18. Hagan JB, Fasano MB, Spector S, Wasserman RL, Melamed I, Rojavin MA, Zenker O, Orange JS. Efficacy and safety of a new 20\% immunoglobulin preparation for subcutaneous administration, IgPro20, in patients with primary immunodeficiency. J Clin Immunol. 2010;30(5):734-45.

19. Borte M, Pac M, Serban M, Gonzalez-Quevedo T, Grimbacher B, Jolles S, Zenker O, Neufang-Hueber J, Belohradsky B. Efficacy and safety of Hizentra ${ }^{\oplus}$, a new 20\% immunoglobulin preparation for subcutaneous administration, in pediatric patients with primary immunodeficiency. J Clin Immunol. 2011; 31(5):752-61.

20. HyQvia ${ }^{\oplus}$ (immune globulin infusion 10\% [human] with recombinant human hyaluronidase) [prescribing information]. Lexington, MA: Baxalta US Inc., 2014.

21. Bienvenu B, Cozon G, Hoarau C, Pasquet M, Cherin P, Clerson P, Hachulla E, Crave JC, Delain JC, Jaussaud R. Does the route of immunoglobin replacement therapy impact quality of life and satisfaction in patients with primary immunodeficiency? Insights from the French cohort "visages". Orphanet J Rare Dis. 2016;11(1):83.

22. Cuvitru ${ }^{\oplus}$ (immune globulin subcutaneous [human], 20\% solution) [prescribing information]. Westlake Village, CA; Baxalta US Inc., 2016.

23. Cuvitru ( $200 \mathrm{mg} / \mathrm{mL}$ solution for subcutaneous injection) [prescribing information]. Vienna, Austria: Baxalta Innovations, GmbH, 2016.

24. Nicolay U, Haag S, Eichmann F, Herget S, Spruck D, Gardulf A. Measuring treatment satisfaction in patients with primary immunodeficiency diseases receiving lifelong immunoglobulin replacement therapy. Qual Life Res. 2005;14(7):1683-91.

25. Perez EE, Orange JS, Bonilla F, Chinen J, Chinn IK, Dorsey M, El-Gamal Y, Harville TO, Hossny E, Mazer B, et al. Update on the use of immunoglobulin in human disease: a review of evidence. J Allergy Clin Immunol. 2017; 139(3S):S1-S46.

26. Shabaninejad H, Asgharzadeh A, Rezaei N, Rezapoor A. A comparative study of intravenous immunoglobulin and subcutaneous immunoglobulin in adult patients with primary immunodeficiency diseases: a systematic review and meta-analysis. Expert Rev Clin Immunol. 2016;12(5):595-602.

27. Abolhassani H, Sadaghiani MS, Aghamohammadi A, Ochs HD, Rezaei N. Home-based subcutaneous immunoglobulin versus hospital-based intravenous immunoglobulin in treatment of primary antibody deficiencies: systematic review and meta analysis. J Clin Immunol. 2012; 32(6):1180-92.

28. Kobrynski L. Subcutaneous immunoglobulin therapy: a new option for patients with primary immunodeficiency diseases. Biologics. 2012;6:277-87.

29. Wasserman RL. Progress in gammaglobulin therapy for immunodeficiency: from subcutaneous to intravenous infusions and back again. J Clin Immunol. 2012;32(6):1153-64.

30. Kearns S, Kristofek L, Bolgar W, Seidu L, Kile S. Clinical profile, dosing, and quality-of-life outcomes in primary immune deficiency patients treated at home with immunoglobulin G: data from the IDEaL patient registry. J Manag Care Spec Pharm. 2017;23(4):400-6.

31. Mallick R, Jolles $S$, Kanegane $H$, Agbor-Tarh D, Rojavin M. Treatment satisfaction with subcutaneous immunoglobulin replacement therapy in patients with primary immunodeficiency: a pooled analysis of six Hizentra ${ }^{\circledR}$ studies. J Clin Immunol. 2018;38(8):886-97. 
32. Vultaggio A, Azzari C, Milito C, Finocchi A, Toppino C, Spadaro G, Trizzino A, Baldassarre M, Paganelli R, Moschese V, et al. Subcutaneous immunoglobulin replacement therapy in patients with primary immunodeficiency in routine clinical practice: the VISPO prospective multicenter study. Clin Drug Investig. 2015;35(3):179-85.

33. Canessa C, lacopelli J, Pecoraro A, Spadaro G, Matucci A, Milito C, Vultaggio A, Agostini C, Cinetto F, Danieli MG, et al. Shift from intravenous or 16\% subcutaneous replacement therapy to $20 \%$ subcutaneous immunoglobulin in patients with primary antibody deficiencies. Int J Immunopathol Pharmacol. 2017;30(1):73-82.

34. Niebur HB, Duff CM, Shear GF, Nguyen D, Alberdi TK, Dorsey MJ, Sleasman JW. Efficacy and tolerability of $16 \%$ subcutaneous immunoglobulin compared with $20 \%$ subcutaneous immunoglobulin in primary antibody deficiency. Clin Exp Immunol. 2015;181(3):441-50.

35. International Patient Organisation for Primary Immunodeficiencies. IPOPI PID Patient Needs \& Outlooks Survey. A Report Based on 300 Patient Questionnaires. 2017. https://ipopi.org/wp-content/uploads/2017/07/IPOPIPID-Patient-Survey-Shortened-Report-030812_Final-IPOPI-format.pdf.

\section{Publisher's Note}

Springer Nature remains neutral with regard to jurisdictional claims in published maps and institutional affiliations.

Ready to submit your research? Choose BMC and benefit from:

- fast, convenient online submission

- thorough peer review by experienced researchers in your field

- rapid publication on acceptance

- support for research data, including large and complex data types

- gold Open Access which fosters wider collaboration and increased citations

- maximum visibility for your research: over $100 \mathrm{M}$ website views per year

At BMC, research is always in progress.

Learn more biomedcentral.com/submissions 